\title{
Contributions of the GIS and the MNT in the Study of the Landscape Morphogenesis of the Area Goulmima-Errachidia (Morocco)
}

\author{
Ridouane Sadki, Mohammed El Wartiti, Sanae Berred, Rajae Azelmad \\ Laboratory of Engineering Geology, Faculty of Science, University Mohammed V, Rabat, Morocco \\ Email: r.sadki@hotmail.fr, wartiti@hotmail.com, berredsanae@gmail.com,rajazelmad@gmail.com
}

How to cite this paper: Sadki, R., El Wartiti, M., Berred, S. and Azelmad, R. (2016) Contributions of the GIS and the MNT in the Study of the Landscape Morphogenesis of the Area Goulmima-Errachidia (Morocco). Journal of Geographic Information System, 8, 729-736.

http://dx.doi.org/10.4236/jgis.2016.86056

Received: September 12, 2016

Accepted: December 26, 2016

Published: December 29, 2016

Copyright $\odot 2016$ by authors and Scientific Research Publishing Inc. This work is licensed under the Creative Commons Attribution International License (CC BY 4.0).

http://creativecommons.org/licenses/by/4.0/

(c) (i) Open Access

\begin{abstract}
Oasis of the Rheris is located in the South-East of Morocco in the province of Errachidia, in the region of Draa-Tafilalt. This zone of study contains in its administrative unit the municipality of Goulmima, and two rural communes: Gheris El Ouloui and Gheris Essoufli. The cretaceous basin of Gheris constitutes of the principal geomorphological entities is limited by the carbonated Jurassic High-Atlas in Tadighoust in north and west. In the south, the Anti-Atlas chain of Mellab and Tinjdad is dominated by a Precambrian base which supports with its back a thick cover of the Paleozoic. And in the center there is Rheris Oasis which characterizes this bioclimatic zone. This oasis looks like an island in the saharan desert. Finally, Hammada de Meski is located in the east. In the tourist literature of Morocco, it mentions the gravitational landscapes in the south of Morocco, of which are geomorphosites of Goulmima that offer superb landscapes. From my point of view, the primary reason behind this research task is to promote geo-eco-tourism for sustainable development of this area. Several tourists cross the zone of study, especially Amellagou-Tinjdad circuit because they are attracted much when they arrive at the beautiful landscape of Rheris, such as geomorphlogical landscape (Tifounassine: full of fresh water). There are many other sources like Tamda N'mssoud, Boukhazm and Asdram of a distance from important observation which offers a beautiful vision on the synclinorium infracenomanian. According to Panizza (2001), the geomorphosites are forms of the relief which have acquired a scientific, cultural and historical, aesthetic, didactic and/or socio-economic value because of their perception. The cartography of the geomorphosites fundamentally aims at giving to the users an immediate perception of the space distribution and representation of the forms of the relief [1]. Today, the use of the Geographical Information Systems has acquired an important growing because of the possibilities of update and interaction with the user with a view to natural regional planning. The digital models of ground (MNT), extracted from the
\end{abstract}


satellite pictures offer valuable help for the analysis and the detailed cartography of the reliefs. The GIS applied to the geographical zone of Goulmima led to the construction and the reading of the results produced by several cards sets of themes.

\section{Keywords}

Morphogenesis, Goulmima, Errachidia, Satellite Picture, MNT

\section{Introduction}

The zone of study is located in the area of Errachidia (south east of Morocco, west of Errachidia city) (Figure 1). The synclinal depression of Goulmima belongs to the furrow pre-African which contains the cretaceous basin of Rheris. It is geographically limited by the High Atlas of Tadighoust and that of Aghbalou N' kerdous to the north and the west respectively, by Hamada de Meski in the east and the Anti-Atlas in the south [2].

The geographical positioning of the zone and the landscape grounds is taken by satellite picture of Google Earth (Figure 2). To have a complete idea, we have proposed to the reader a menu of few photographs emphasized by GIS and MNT (Figure 3).

\section{Equipments and Methods}

This work exposes the contribution of the GIS and the Digital Model of Ground (MNT) in the study of geomorphological of the selected sites of the area of study [3]. The MNT

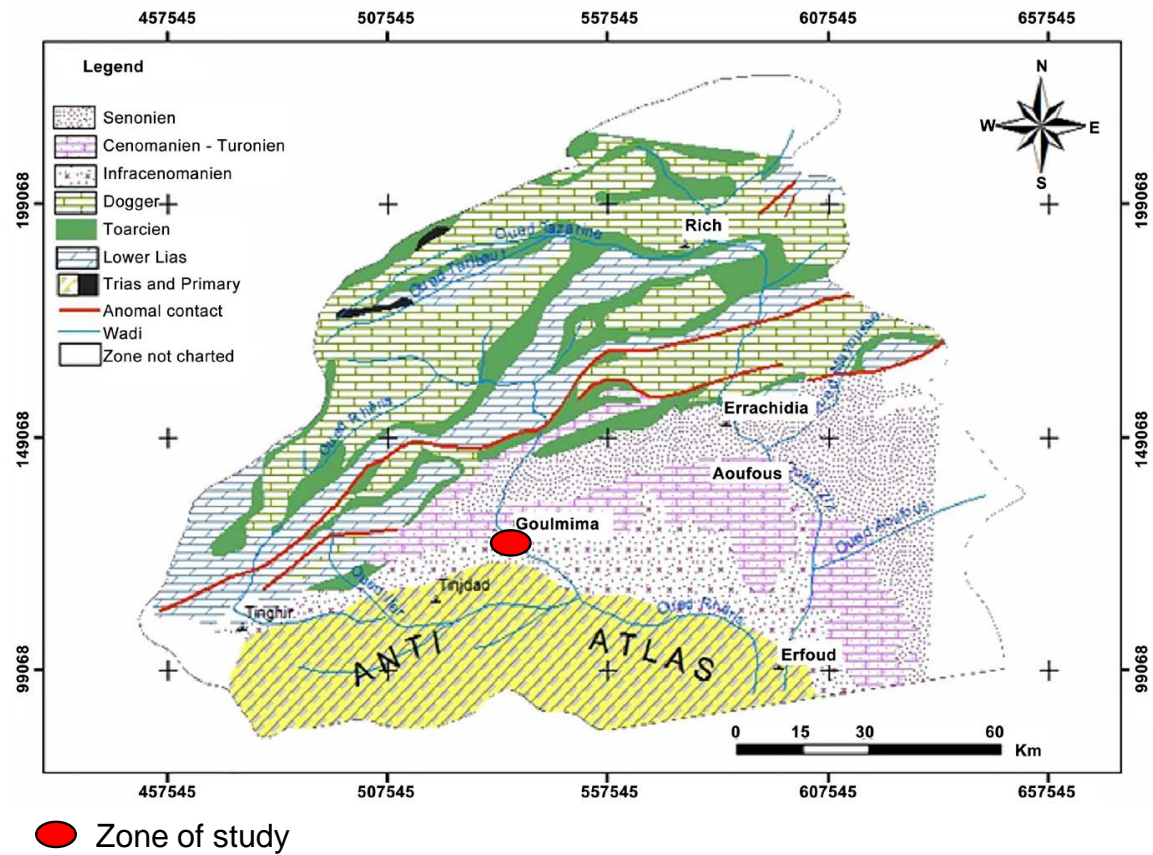

Figure 1. Simplifie geological map of basins of the Wadi Ziz and Wadi Rheris "high central atlas and cretaceous basin of Errachidia" Jarar Oulidi et al., 2005. 


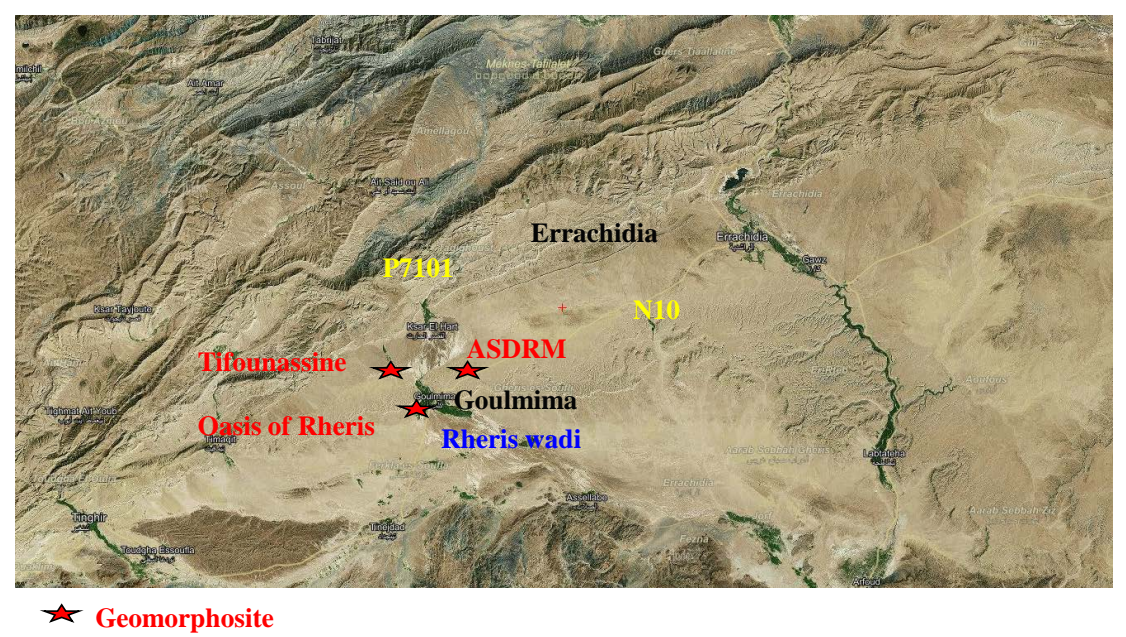

Figure 2. Geographical position of the area of study and the geosites (satellite picture of the zone Goulmima-Errachidia (Google Earth)).

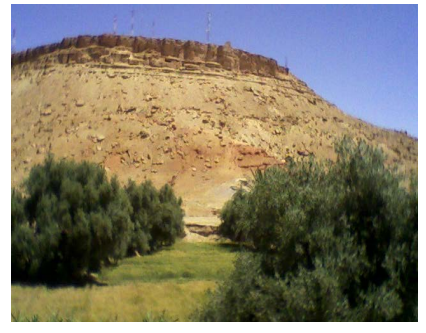

Photograph 1: Balcony of ASDRM

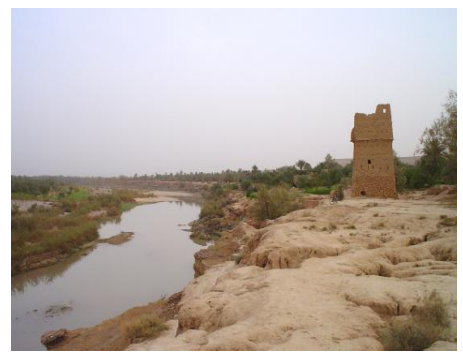

Photograph 3: Picturesque landscape of the Lake Tifounassine

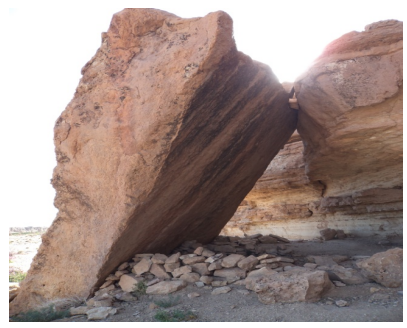

Photograph 2: Particular landscape of Turonien

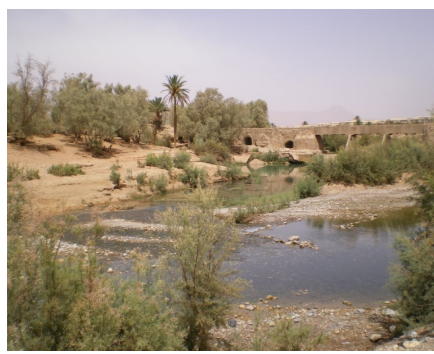

Photograph 4: Panoramic landscape of Tifounassine

Figure 3. Photographs of different landscapes showing the geomorphosites emphasized by GIS and MNT.

can be obtained by various manners: by scanning and digitalization of topographic cards or by treatment of imagery stereoscopic Radar. In our work, we obtained the MNT via using radar images (SRTM: Shuttle Radar Topography Mission) with a resolution of $90 \mathrm{~m}$.

\section{Results and Discussion}

The MNT makes it possible to individualize well the various geomorphological formations of the zone study. Indeed, the obtained results show two types. Relief of high alti- 
tude formed by Turonien of the balcony of ASDRM in yellow color, and the low blue relief represented by the plain of Rheris, formed by quaternary alluvial deposits [4] (Figure 4). From the MNT, we carried out a synthetic topographic profile of the zone of study (see Figure 5).

The topographic profile realized in the zone area starting from the panoramic landscape of the balcony of ASDRAM, crossing the panoramic landscape of Tifounassine

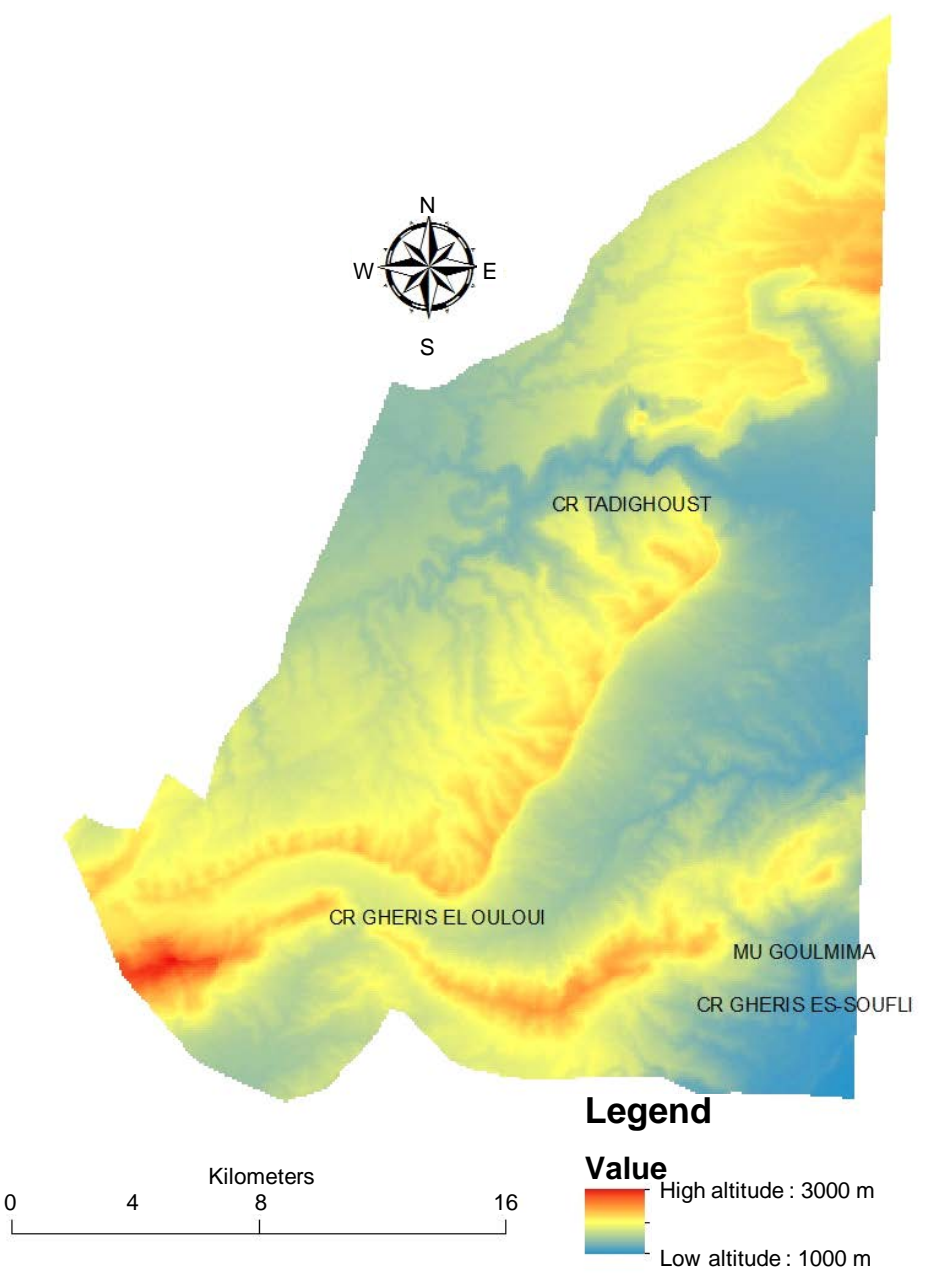

Figure 4. MNT of Goulmima taken by a radar image SRTM.

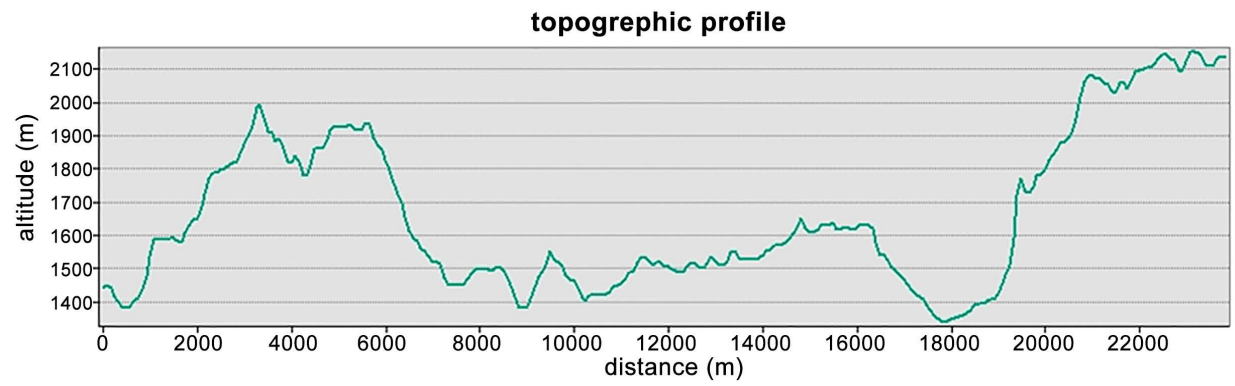

Figure 5. Topographic profile across the panoramic landscape of Tifounassine. 
towards the chain of high Atlas in Tadighoust This lake morphology is between two reliefs of high altitudes.

The landscape of ASDRM is panoramic when seeing the Oasis of Rheris from a high area. It is good for practising sport (going up and down).

Several cards sets of themes were extracted from the MNT namely: the map of the slopes, orientation, shade and the hydrographic network.

The map of the slopes (Figure 6) shows that the zone is generally characterized by a slope from $20 \%$ to $40 \%$. Consequently, the loss of the deposits remains weak at average. It is a preserving zone of these deposits.

The map of orientation (Figure 7) shows:

The reliefs of Turonien and Jurassic show the same north-western direction, while the Oasis and the panoramic landscape of Tifounassine also follow the same southeastern direction.

The lake Tifounassine and the Oasis of Rheris are considered as receiving zones of the formations subjected to the erosion of the reliefs of secondary age.

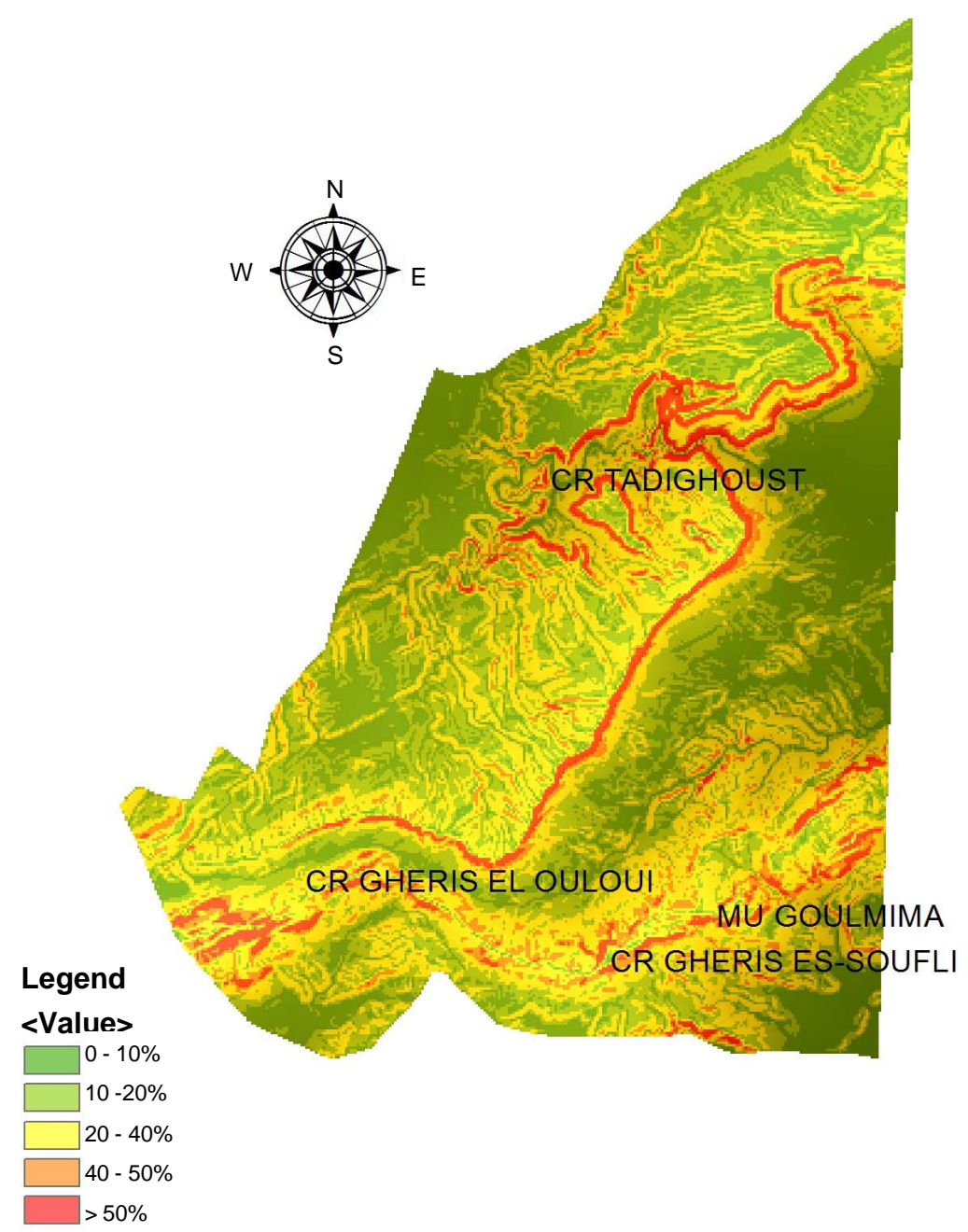

Figure 6. Map of the slopes. 

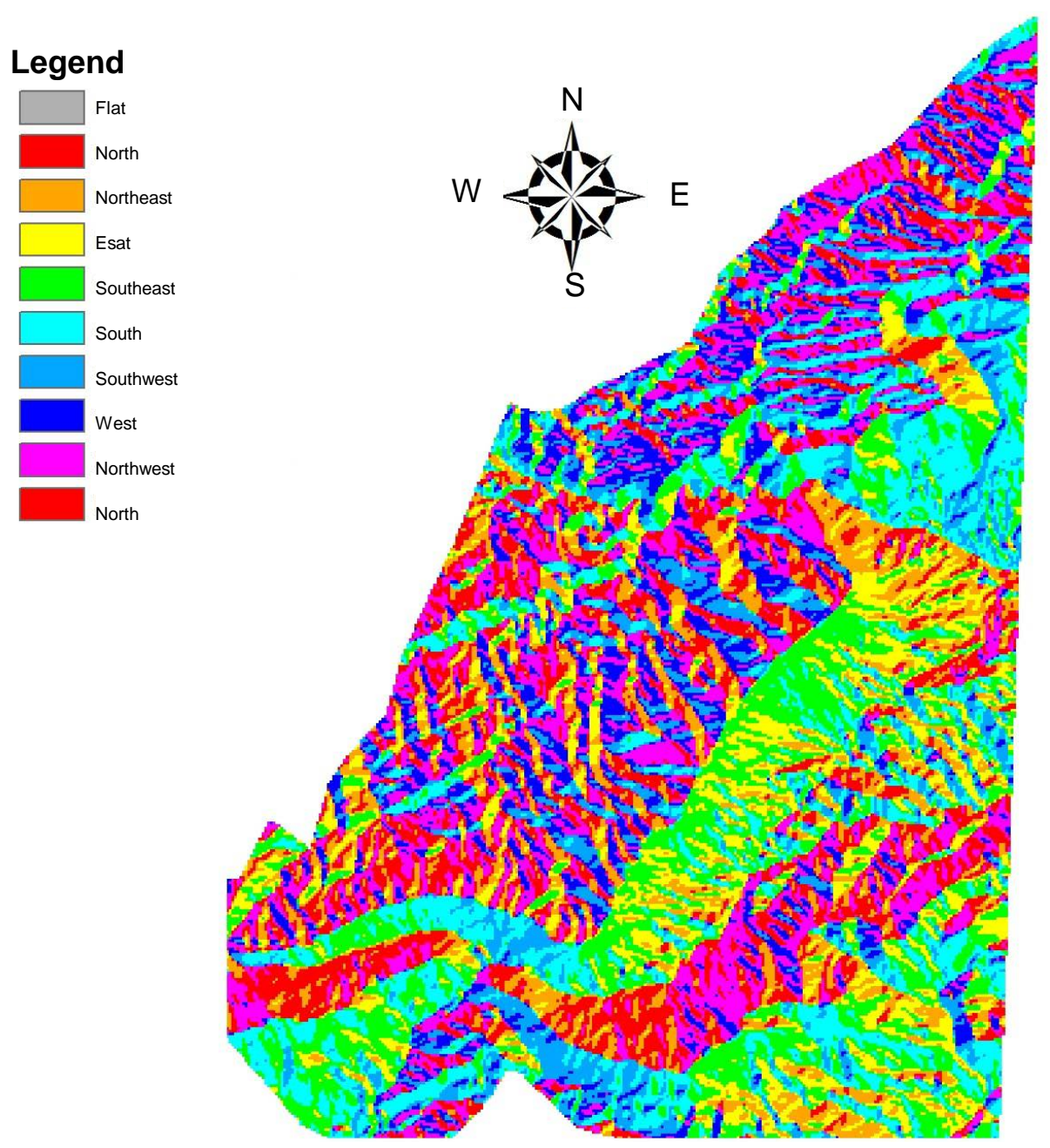

Figure 7. Map of orientation.

The map of shade (Figure 8) and visualization in 3D, using tool GIS shows the geomorphology clearly and facilitates their spacial follow-up and their enumeration.

We observe two geomorphological units with light gray and two others with dark gray.

The MNT is subjected to several treatments knowing the realization of the relative layers "flow direction" and consequently the automatic regeneration of the hydrographic network of the zone of study. The comparison with the hydrographic network identified in the topographic cards, shows a good similarity, especially for the boxed wadis (Rheris Wadi) [5]. The analysis of this network shows two principal directions (Figure 9). First, it is a north-south mountain of Amellagou and Tadighoust. The second direction is west-east of the Wadi El Bour in Tinjdad. The third one is east in Tamda N'messaoud. In fact, these three affluents constitute the Rheris river.

The two first constitute the principal waterways of Atlas origin of the Rheris River which feed the quaternary and infracenomanian ground water and the palm plantation in Goulmima [6]. 


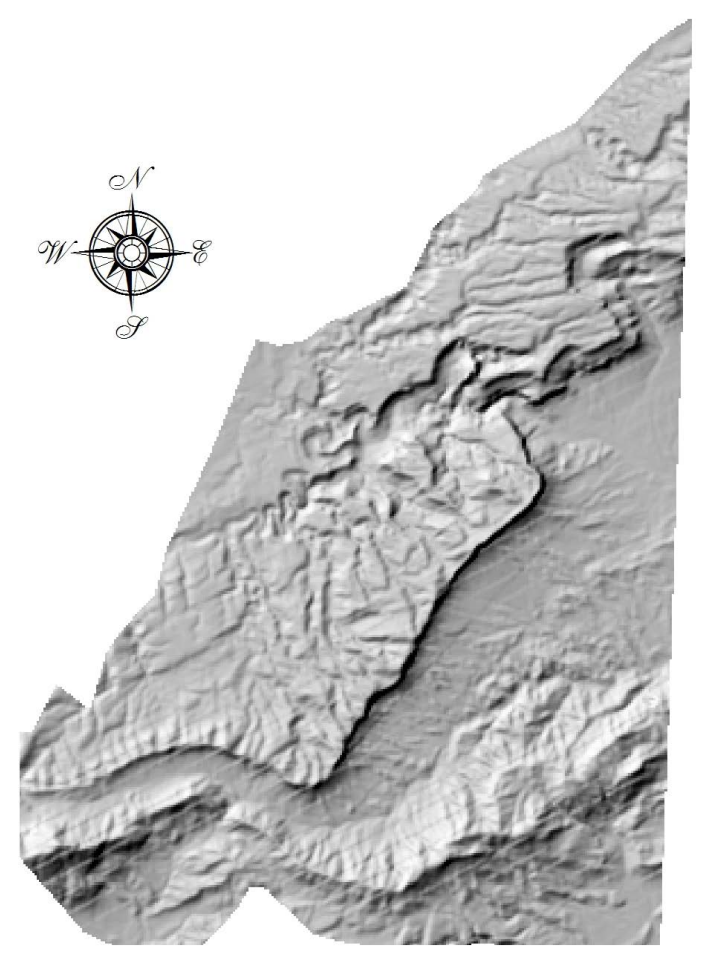

Figure 8. Map of shade.

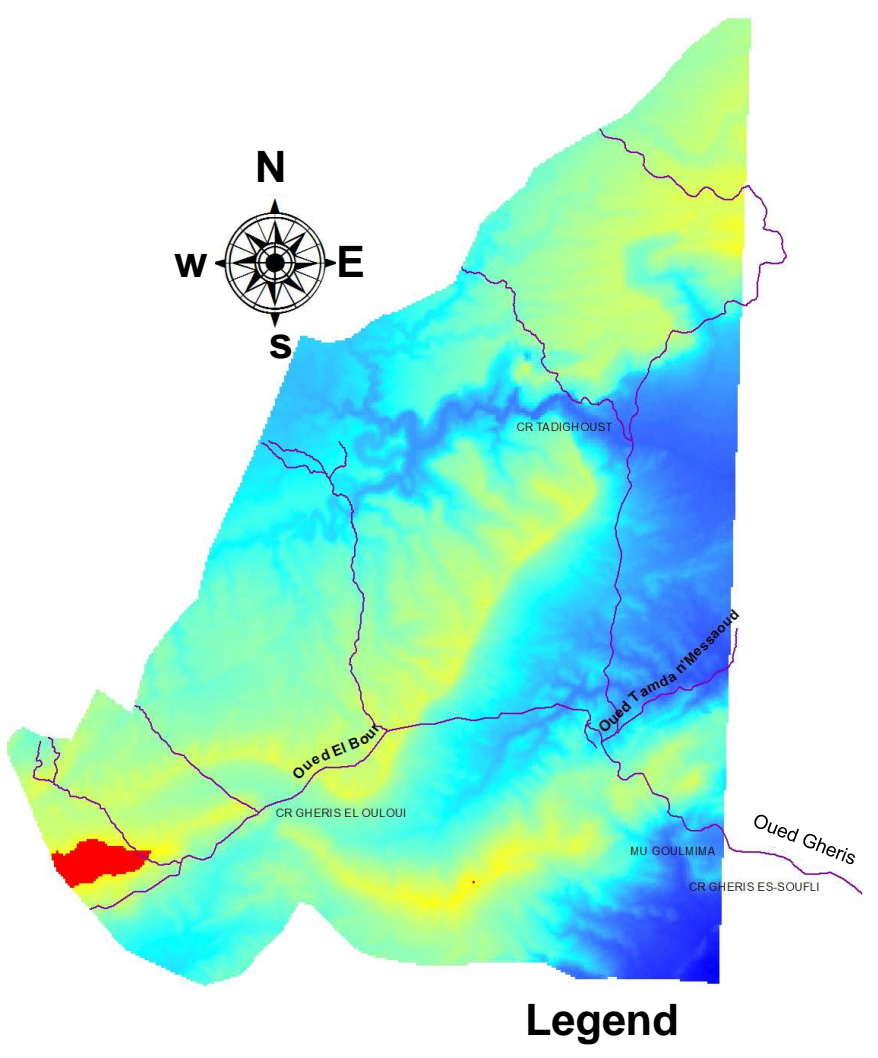

Figure 9. Map of the hydrographic network. 


\section{Conclusion}

The use of tool GIS and the image SRTM radar made it possible to have other information sources for understanding the geomorphological aspects of the studied ground well. The MNT made it possible to individualize well the various geomorphological formations with their number, direction... Thus, the current splendid moulding of the landscape has been generated by continued erosion since the Neogene until now. Other information was extracted from the MNT with the edition from the cards sets of themes related to the hydrographic network, the slope, the shade, the model 3D and realization of several topographic profiles. These results, obtained from the development of cartographic documents, facilitate an orientation of the public policies for a better regional planning based on scientific good decisions and a promotion of a possible regional sustainable development.

\section{References}

[1] Di Gregorio, M.F., Wartiti, M., Fadli D. and Zahraoui, M. Geosites, Geomorfosites, Geodiversity and Geological Landscape: New Resources for Bearable Tourism in University of Cagliari. University of Rabat, Rabat, 8 p.

[2] Fluvial Formations of the Higher Pleistocene and Holocene of the "Plain" of Tazoughmit (Rheris River, Piedmont South-Atlas of Goulmima, Morocco), 19 p.

[3] Intensive Course on Geomorphosites: Beni Mellal. Faculty of Letters and Social Sciences, 1 October 2014, $66 \mathrm{p}$.

[4] Impact of Climate Changes and Anthropic on the Water Resources in the Oasis of Ferkla (Tinjdad, Goulmima, Errachidia, Morocco), Lahcen KABIRI, 52 p.

[5] Study of the Development Project of the Rural Communes through Restoration of Khettaras in the Semi-Arid Areas of the East South of Atlas. International Japanese Cooperation, December 2005, 104 p.

[6] Ammary, B. Geochimcal and Isotopic Study of Principal Ground Water of the Cretaceous Basin of Errachidia and the Plain of Tafilalet, Doctorate, Faculty of Sciences, University Mohammed V, Rabat, 134 p.

Submit or recommend next manuscript to SCIRP and we will provide best service for you:

Accepting pre-submission inquiries through Email, Facebook, LinkedIn, Twitter, etc.

A wide selection of journals (inclusive of 9 subjects, more than 200 journals)

Providing 24-hour high-quality service

User-friendly online submission system

Fair and swift peer-review system

Efficient typesetting and proofreading procedure

Display of the result of downloads and visits, as well as the number of cited articles

Maximum dissemination of your research work

Submit your manuscript at: http://papersubmission.scirp.org/

Or contact jgis@scirp.org 